\title{
Short term effects of indomethacin on rat small intestinal permeability. Role of eicosanoids and platelet activating factor
}

\author{
F Mion, J-C Cuber, Y Minaire, J-A Chayvialle
}

\begin{abstract}
Short term effects of indomethacin on intestinal permeability were studied on a model of rat isolated vascularly perfused terminal ileum. The objectives of this study were (a) to assess the effects of indomethacin on intestinal permeability and histology; (b) to assess the effects of prostaglandins, leukotrienes, and platelet activating factor (PAF) on the same parameters; (c) to evaluate the role of these inflammation mediators on indomethacin induced permeability modifications. Intravascular administration of 1.25 and $2.5 \mathrm{mM}$ indomethacin induced a significant increase of ${ }^{51} \mathrm{Cr}$-EDTA transfer rate. Histological analysis showed only mucosal oedema. Pretreatment with 16,16 dimethyl-prostaglandin $\mathbf{E}_{2}$ did not reverse these changes. Intravascular administration of PAF, leukotrienes $B_{4}$ and $D_{4}$ provoked a significant rise in ${ }^{51} \mathrm{Cr}$-EDTA transfer rate and intraluminal protein leakage, with an intense vascocongestion of the mucosal capillaries. These changes were completely prevented by perfusion of the respective specific antagonists (BN52021 for PAF, LY255,583 for leukotriene $B_{4}$ and MK571 for leukotriene $D_{4}$ ). None of these three antagonists, however, or MK886, a selective $5^{\prime}$-lipo-oxygenase inhibitor, could reverse the indomethacin induced permeability changes. Indomethacin induced increased intestinal permeability at these high concentrations does not seem to be a result of changed prostanoid or PAF metabolism. Alternative mechanisms of the initial damage of non-steroid anti-inflammatory drugs should be sought.
\end{abstract}

(Gut 1994; 35: 490-495)

In humans, longterm treatment with nonsteroidal anti-inflammatory drugs (NSAIDs) can induce an increase in small intestinal permeability. ${ }^{12}$ This phenomenon is supposed to be an early event occurring after NSAID administration, leading to intestinal inflammation by eliciting the toxic action of exogenous compounds such as food and bacteria ${ }^{34}$ on a damaged intestinal mucosa. The exact mechanisms, however, leading to increased permeability remain largely unknown.

NSAIDs are potent inhibitors of cyclooxygenase, and the decreased production of endogenous prostaglandins could favour increased permeability. It has been shown that exogenous prostaglandins can decrease indomethacin induced permeability changes, ${ }^{5}$ although no clear relation between cyclo- oxygenase inhibition and the occurrence of intestinal lesions has been established. ${ }^{6}$ Alternatively, increased local production of leukotrienes could lead to increased intestinal permeability ${ }^{78}$ : NSAIDs may increase leukotriene synthesis by diversion of the arachidonic acid cascade towards the lipo-oxygenase pathway. ${ }^{\text {? }}$

Platelet activating factor (PAF), the most potent ulcerogenic agent, may be another contender for increased intestinal permeability, by induction of dramatic changes in the mucosal vasculature ${ }^{9}$ or through its action on neutrophils. ${ }^{10}$ Its local production may be stimulated by NSAIDs, either directly or through the development of an inflammatory response. ${ }^{11}$

The aims of this study were to show in an ex vivo model of isolated vascularly perfused ileum of the rat, the effects of indomethacin on small intestinal permeability, and to assess the role of prostaglandin $E_{2}$, leukotriene $B_{4}$, leukotriene $\mathrm{D}_{4}$, and PAF in the indomethacin induced changes.

\section{Materials and methods}

MATERIALS

The following reagents were purchased: indomethacin powder, 16,16-dimethyl prostaglandin $E_{2}\left(5 \mathrm{mg} / \mathrm{ml}\right.$ ethanol), leukotrienes $B_{4}$ and $D_{4}$ (in ethanol solution), PAF (L-A-phosphatidylcholin, B-acetyl-gamma-O-alkyl) (2 $\mathrm{mg} / \mathrm{ml}$ chloroform), from Sigma Chemical; bovine serum albumin $30 \%$ (BSA), from BioMérieux, France; Azonutril 25 (a mixture of amino acids) from Laboratoire Roger Bellon, France; ${ }^{51} \mathrm{Cr}$ EDTA complex $\left({ }^{51} \mathrm{Cr}\right.$-EDTA in $5 \mu \mathrm{M}$ EDTA, $\mathrm{pH}=7 \cdot 0, \mathrm{SA}=300 \mu \mathrm{Ci} / \mu \mathrm{L}$ ) from New England Nuclear. The following antagonists were provided: LY 255,583 (a specific leukotriene $B_{4}$ receptor antagonist) by Lilly Laboratories ${ }^{12}$; MK-571 (a specific leukotriene $D_{4}$ receptor antagonist) by Merck Sharp and Dohme Research Laboratories ${ }^{13}$; MK-886 (a selective leukotriene synthesis inhibitor) by Merck Frosst Centre for Therapeutic Research ${ }^{14}$; and BN 52021 (a specific PAF receptor antagonist) by Institut Henri Beaufour. ${ }^{15}$

\section{SURGICAL PREPARATION}

The surgical steps of the rat isolated vascularly perfused ileum have been reported in detail. ${ }^{16}$ Male Wistar rats (250-350 g) were anaesthetised with pentobarbital-sodium $(50 \mathrm{mg} / \mathrm{kg}$, intraperitoneal). After opening the abdomen by a midline incision, the right and middle colic arteries were tied and cut off. A loop of terminal Dr F Mion, pavillon $\mathrm{H}$ bis, Lyon cedex 03, France. Accepted for publication 9 August 1993 
ileum (10 cm length) was isolated: both ends of the loop were catheterised with Silastic tubing and the lumen of the intestine flushed twice with $10 \mathrm{ml}$ prewarmed isotonic saline. A metal cannula $(0.6 \mathrm{~mm}$ inside diameter, $0.8 \mathrm{~mm}$ outside diameter) was quickly (within $30 \mathrm{~s}$ ) inserted in the superior mesenteric artery, and a Silastic one $(0.9 \mathrm{~mm}$ inside diameter, $1.2 \mathrm{~mm}$ outside diameter) was introduced into the portal vein. The vascular perfusion was immediately started at a rate of $1.5 \mathrm{ml} / \mathrm{min}$. The perfused solution was a Krebs-Henseleit solution ( $\mathrm{pH} 7 \cdot 4$ ) containing $25 \%$ washed bovine erythrocytes, $3 \%$ BSA, $5 \mathrm{mM}$ glucose, and $1 \%$ azonutril. This mixture was continuously gassed with $95 \%$ oxygen $/ 5 \%$ carbon dioxide and warmed at $37^{\circ} \mathrm{C}$. The vascular perfusion pressure was permanently monitored from a $\mathrm{T}$ connector located in the arterial perfusion system. The ileal loop was then transferred into a temperature stable $\left(37^{\circ} \mathrm{C}\right)$ plastic box filled with isotonic saline. Intestinal lumen was continuously perfused with isotonic saline at a flow rate of $0.5 \mathrm{ml} / \mathrm{min}$. Both vascular and luminal perfusions were performed without recirculation (open system) and the effluents were collected as five minute fractions throughout the study. Perfusion time was limited to 120 minutes for all experiments.

\section{EXPERIMENTAL DESIGN}

Pharmacological manipulations of the isolated ileum were always started after a 20 minute control basal period. Indomethacin, eicosanoids, and their various antagonists were given in the vascular perfusion system either as a constant perfusion or as a bolus through a catheter close to the arterial inflow. The doses chosen were derived from previously reported studies. All drugs were dissolved in a $3 \%$ BSA enriched Krebs-Henseleit solution just before they were given. Indomethacin was first dissolved in dimethyl sulphoxide ( $90 \mathrm{mg}$ indomethacin in $\mathbf{4 0 0}$ $\mu \mathrm{l})$, neutralised with $1 \mathrm{~N}$ sodium hydroxide, and brought to the final concentration with 3\% BSA enriched Krebs-Henseleit solution. ${ }^{17}$ For each drug studied, control experiments consisted of administration of the drug solvent (KrebsHenseleit solution plus $0 \cdot 4 \%$ dimethyl sulphoxide for indomethacin, $0 \cdot 1 \%$ ethanol for leukotrienes and dimethyl prostaglandin $\mathbf{E}_{2}$, $0.05 \%$ chloroform for PAF, $0 \cdot 1 \%$ mannitol for BN52021).

\section{INTESTINAL PERMEABILITY STUDIES}

The vascular to ileal lumen passage of albumin (as a marker of vascular permeability) ${ }^{18}$ was estimated by measuring the amount of protein present in the luminal effluent/unit of time. ${ }^{19}$ The vascular to lumen ${ }^{51} \mathrm{Cr}$-EDTA transfer rate (R) has been well established as a marker of epithelial permeability. ${ }^{20}$ It was assessed by the percentage of radioactivity detected in the luminal effluent when ${ }^{51} \mathrm{Cr}$-EDTA was infused in the vascular system at a constant rate (about $10000 \mathrm{cpm} / \mathrm{ml}$ of vascular perfusate). ${ }^{21}$ The percentage was calculated as the following ratio:

$$
\mathrm{R}=\left(\mathrm{C}_{\text {lum }} \times \mathrm{Q}_{\text {lum }} \times 100\right) /\left(\mathrm{C}_{\text {vasc }} \times \mathrm{Q}_{\text {vasc }}\right)
$$

where $\mathrm{C}_{\text {lum }}$ and $\mathrm{C}_{\text {vasc }}$ represent $\mathrm{cpm} / \mathrm{ml}$ of ${ }^{51} \mathrm{Cr}$ EDTA in the luminal effluent and the vascular perfusate respectively; $Q_{\text {lum }}$ and $Q_{\text {vasc }}$ represent the luminal and vascular perfusion rates $(0.5$ and $1.5 \mathrm{ml} / \mathrm{min}$ respectively).

\section{VIABILITY STUDIES}

Oxygen and glucose consumption have been previously assessed in this model. ${ }^{16}$ Epithelium injury was assessed by measuring lactate dehydrogenase release in the vascular and luminal effluents. In preliminary studies, we found that lactate dehydrogenase release was considerably increased after a 10 minute period of ischaemia and reperfusion of the ileal loop (data not shown); we therefore used this parameter as a marker of epithelial integrity. The vascular perfusion pressure (mean (SEM)) remained stable $(45$ (5)) $\mathrm{mm} \mathrm{Hg}$ throughout control experiments.

\section{HISTOLOGICAL ANALYSIS}

At the end of the perfusion experiments, perfused intestinal loops were removed, fixed in Bouin solution, embedded in paraffin wax, and stained with haematoxylin and eosin for histological analysis.

\section{STATISTICAL ANALYSIS}

The data in all figures are presented as mean (SEM) values. Results were compared using the Student's $t$ test for unpaired values, with $\mathrm{p}<0.05$ as the significance threshold.

\section{Results}

\section{INTRAVASCULAR PERFUSION OF INDOMETHACIN}

Permeability effects - In control experiments, permeability remained stable throughout the 120 minute perfusion (luminal protein concentration less than $100 \mu \mathrm{g} / \mathrm{ml}$; ${ }^{51} \mathrm{Cr}$-EDTA $\mathrm{R}=0 \cdot 2 \%(0 \cdot 1)$,

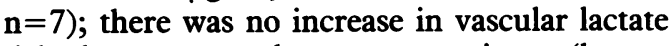
dehydrogenase release over time (lactate dehydrogenase $=16.4(1.4) \mathrm{IU} / \mathrm{l}$ at the beginning of the perfusion, compared with lactate dehydrogenase $=22 \cdot 0(2 \cdot 6)$ after two hours; $p>0 \cdot 1)$. Indomethacin effect was assessed for increasing concentrations (from $0.1 \mathrm{mM}$ to $2.5 \mathrm{mM}$ ). Intestinal permeability changes were detectable only in the presence of 1.25 and $2.5 \mathrm{mM}$ indomethacin (Fig 1). There was a selective increase in ${ }^{51} \mathrm{Cr}$-EDTA transfer rate, starting 30 minutes after the beginning of indomethacin administration. The amount of protein present in the luminal effluent was unchanged $(<100$ $\mu \mathrm{g} / \mathrm{ml}$ throughout the experiments). An increase in lactate dehydrogenase release in the vascular effluent was not seen after $\mathbf{8 0}$ minutes perfusion of $2.5 \mathrm{mM}$ indomethacin (lactate dehydrogenase $=20.8(2.4) \mathrm{IU} / \mathrm{l}$ at the end of the experiment period, not significantly different from controls, $\mathrm{n}=6$ ).

Histological modifications - In the control experiments, histological examination of ileal loops after 120 minutes perfusion showed a normal pattern except for a slight oedema of the 
Figure 1: Effects of indomethacin $(0 \cdot 1-2 \cdot 5 \mathrm{mM})$ on blood to lumen ${ }^{51} \mathrm{Cr}$ EDTA permeability of rat ileal loops. Indomethacin was given intravascularly. $A$ significant increase $(p<0.05)$ was seen for the highest concentrations of indomethacin $(1 \cdot 25$ and 2.5 $\mathrm{mM}), 30$ minutes after the start of the perfusion.

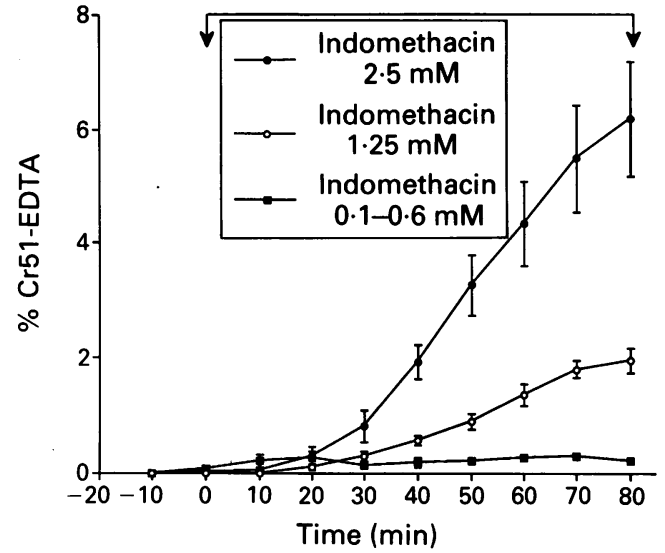

lamina propria (Fig 2), as previously described. ${ }^{15}$ After vascular perfusion of 1.25 and $2.5 \mathrm{mM}$ indomethacin, histological analysis essentially showed appreciable oedema of the lamina propria as well as the submucosa; lymphatic dilation was also noticeable (Fig 3).

\section{6,16-DIMETHYL PROSTAGLANDIN E 2} PERMEABILITY EFFECTS

Intravascular or intraluminal administration of $2.5 \mu M$ 16,16- dimethyl prostaglandin $\mathrm{E}_{2}$ did not produce any ${ }^{51} \mathrm{Cr}$-EDTA transfer rate increase or histological changes (data not shown). Furthermore 16,16-dimethyl prostaglandin $\mathrm{E}_{2}$ did not significantly reduce the indomethacin induced increase of ${ }^{51} \mathrm{Cr}$-EDTA transfer rate, when given 20 minutes before and during $2.5 \mathrm{mM}$ indomethacin perfusion $\left({ }^{51} \mathrm{Cr}\right.$ EDTA R $=3.0 \%(0.2)$ at the end of the perfusion

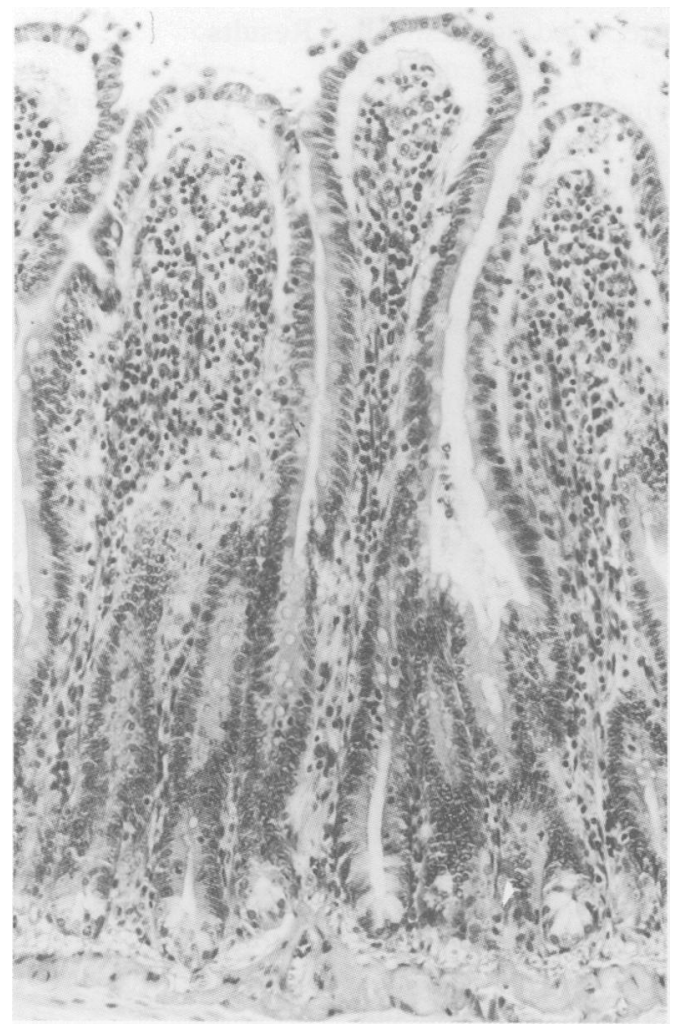

Figure 2: Light microscopic view of an ileal loop section after a 120 minute control perfusion experiment. Note the normal appearance of the villi and the submucosa, and the moderate oedema of the lamina propria. (Haematoxylin and eosin staining, original magnification $\times 60$ ). $(n=4)$, compared with a value of $4 \cdot 3 \%(0 \cdot 7)$ in experiments $(n=6)$ with $2.5 \mathrm{mM}$ indomethacin alone, $\mathrm{p}=0 \cdot 19)$.

\section{PAF INDUCED INTESTINAL ACTIONS}

Intravascular perfusion of PAF $(3 \cdot 2 \mathrm{pM})$ provoked a rapid and significant increase in protein leakage from the vascular bed to ileal lumen (547 (72) $\mu \mathrm{g} / \mathrm{ml} 20$ minutes after PAF was given compared with $<100 \mu \mathrm{g} / \mathrm{ml}$ after PAF solvent perfusion, $\mathrm{p}<0.01$ ), with a concomitant rise of the perfusion pressure $(+27(5) \mathrm{mm} \mathrm{Hg}$ compared with +5 (2) $\mathrm{mm} \mathrm{Hg}$ in control experiments, $\mathrm{p}<0.01)$. There was also a significant increase of ${ }^{51} \mathrm{Cr}$-EDTA vascular to lumen transfer rate (Fig 4), while no increase in vascular lactate dehydrogenase release was noted. These effects were completely prevented by $0.1 \mathrm{mM}$ BN 52021, starting 10 minutes before the PAF infusion (Fig 4).

The histological pattern was different from indomethacin induced changes: there was a striking dilatation of mucosal capillaries, filled with erythrocytes (Fig 5). Mucosal lymphatic capillaries were also dilated, with moderate submucosal oedema. Histological changes were completely prevented by the vascular perfusion of BN 52021 (data not shown).

EFFECTS OF LEUKOTRIENE $B_{4}$ AND LEUKOTRIENE $D_{4}$ Vascular administration of a bolus of $0.5 \mu \mathrm{g}$ leukotriene $\mathrm{D}_{4}$ increased rapidly and significantly protein leakage $(465(120) \mu \mathrm{g} / \mathrm{ml} 10$ minutes after leukotriene $\mathrm{D}_{4}$ injection, com-

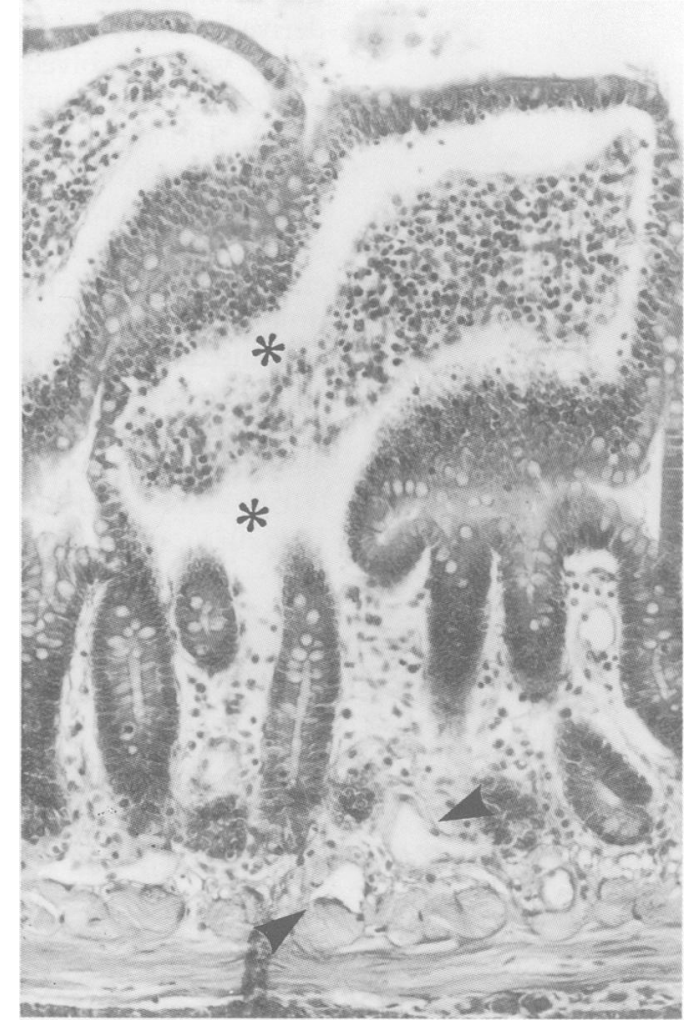

Figure 3: Pathological section of an ileal loop, after 80 minutes of vascular perfusion of $2.5 \mathrm{mM}$ of indomethacin. There is an important mucosal oedema (asterisk), associated with dilated lymphatic capillaries (arrow). (Haematoxylin and eosin staining, original magnification $\times 60$ ). 
Figure 4: Blood to lumen ${ }^{51} \mathrm{Cr}-\mathrm{EDTA}$ permeability changes induced by $P A F$ (3.2 pM). A rapid permeability increase was seen 10 minutes after the start of vascular administration of PAF. This effect was completely prevented by the perfusion of a specific PAF receptor antagonist (BN52021, 0.1 mM), starting 10 minutes before the $P A F$ infusion. $(n=6$ for both experiments; $p<0.001$.)

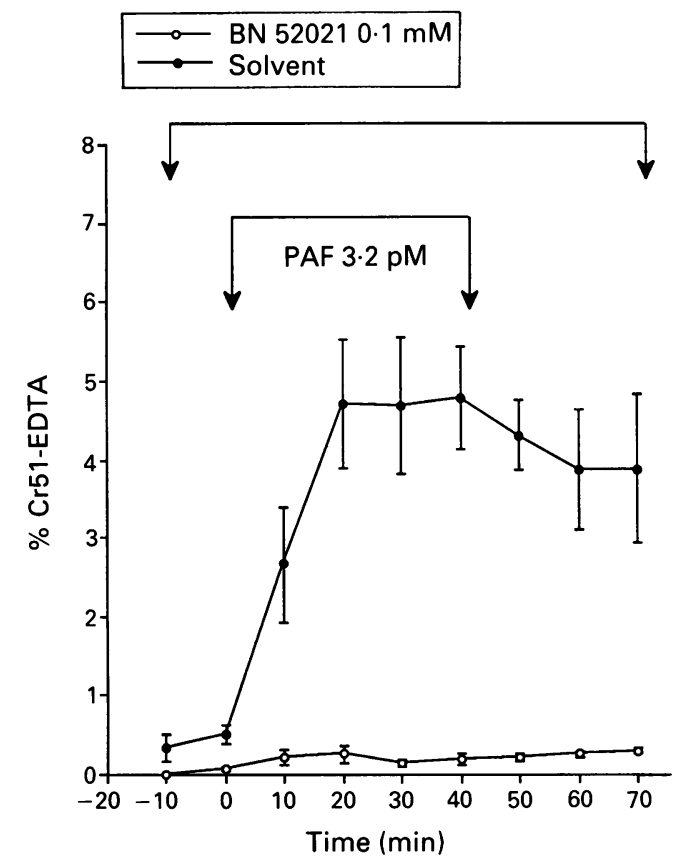

pared with $<100 \mu \mathrm{g} / \mathrm{ml}$ after leukotriene $\mathrm{D}_{4}$ solvent injection, $\mathrm{p}<0.03),{ }^{51} \mathrm{Cr}$-EDTA vascular to lumen permeability ( ${ }^{51} \mathrm{Cr}-\mathrm{EDTR} \mathrm{R}=2 \cdot 95 \%$ $(1 \cdot 16), 10$ minutes after leukotriene $\mathrm{D}_{4}$ injection, compared with $0 \cdot 2 \%(0 \cdot 1)$ after solvent injection, $\mathrm{p}<0.05, \mathrm{n}=4)$ and perfusion pressure $(+22(3)$ $\mathrm{mm} \mathrm{Hg}$ compared with 5 (3) $\mathrm{mm} \mathrm{Hg}$ for controls, $\mathrm{p}<0.05)$. No increase of vascular lactate dehydrogenase release over time was seen. Histological changes were similar to those seen after PAF administration: considerable dilatation of mucosal vascular and lymphatic capillaries were the most striking changes. Complete prevention of increased permeability $\left({ }^{51} \mathrm{Cr}\right.$ EDTA $R=0 \cdot 3 \%(0 \cdot 1) 10$ minutes after leuko-

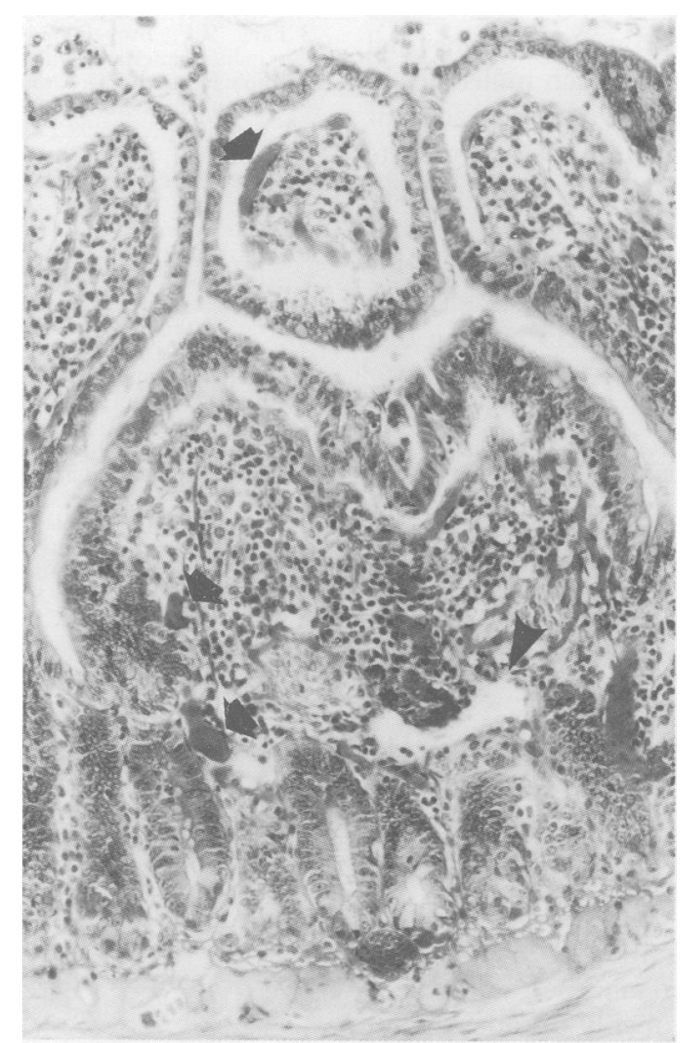

triene $\mathrm{D}_{4}$ injection, protein leakage $<100 \mu \mathrm{g} /$ $\mathrm{ml})$, increased perfusion pressure $(+6(3) \mathrm{mm}$ $\mathrm{Hg}$ after leukotriene $\mathrm{D}_{4}$ injection), and of histological changes was obtained when $0.1 \mathrm{mM}$ MK571, a selective antagonist of leukotriene $D_{4}$, was perfused 10 minutes before and after leukotriene $\mathrm{D}_{4}$ administration.

Higher doses of leukotriene $B_{4}$ were needed to obtain similar changes: $1 \mu \mathrm{g}$ bolus of leukotriene $B_{4}$ induced an increase of protein leakage from the vascular sector into the lumen $(230(95) \mu \mathrm{g} /$ $\mathrm{ml} 10$ minutes after leukotriene $B_{4}$ injection, compared with $<100 \mu \mathrm{g} / \mathrm{ml}$ after solvent injection, $\mathrm{p}<0.05),{ }^{51} \mathrm{Cr}$-EDTA transfer rate $\left({ }^{51}\right.$ Cr-EDTA $R=1.5 \%(0.9) 10$ minutes after leukotriene $\mathrm{B}_{4}$ injection, compared with $0.2 \%$ $(0.1)$ for controls, $p<0.05, n=4)$, increased perfusion pressure $(+12(5) \mathrm{mm} \mathrm{Hg}$ compared with +4 (2) $\mathrm{mm} \mathrm{Hg}$ after solvent injection), and mucosal vascular congestion. The administration of $0 \cdot 1 \mathrm{mM} \mathrm{LY} 255,583$, a selective antagonist of leukotriene $\mathrm{B}_{4}$, completely prevented those acute changes.

\section{EFFECTS OF SPECIFIC ANTAGONISTS OF LEUKOTRIENES AND PAF ON INDOMETHACIN INDUCED PERMEABILITY INCREASE}

When perfused 10 minutes before and during 2.5 $\mathrm{mM}$ indomethacin administration, none of the antagonists (BM 52021, LY255,583, MK571 and MK886) significantly decreased indomethacin induced ${ }^{51} \mathrm{Cr}$-EDTA blood to lumen permeability increase: ${ }^{51} \mathrm{Cr}$-EDTA $\mathrm{R}$ was $4 \cdot 5 \%$ $(0.5)$ after 80 minutes of indomethacin perfusion with $0.1 \mathrm{mM}$ BN52021, 3.8\% (0.1) with $0.1 \mathrm{mM}$ LY255,583, $4.8 \%(0.5)$ with $0.1 \mathrm{mM}$ MK571, and $3.7 \%(0.7)$ with $0.1 \mathrm{mM}$ MK886, compared with a value of $4.3 \%(0.7)$ with $2.5 \mathrm{mM}$ indomethacin alone $(n=5$ for each antagonist, $\mathrm{p}>0 \cdot 1)$. Neither vascular to lumen protein leakage or vascular lactate dehydrogenase release was increased $(<100 \mu \mathrm{g} / \mathrm{ml}$ in each case). The indomethacin induced rise of perfusion pressure was not corrected by any of the four antagonists used.

\section{Discussion}

In the isolated vascularly perfused small bowel model, we have shown that high doses of indomethacin rapidly increased vascular to lumen ${ }^{51}$ Cr-EDTA permeability. Although these high concentrations of indomethacin will probably not be achieved in humans, the doses usually given in animal models to induce intestinal lesions are much higher than those used in clinical practice. ${ }^{34}$ This high dose requirement is probably partly a result of interspecies variations of sensibility to NSAIDs. Our results are in accordance with those of Krugliak et al ${ }^{22}$ : these authors found an increase of PEG 400 intestinal absorption only when 2.5 and $5 \mathrm{mM}$ indomethacin were given.

In our model, indomethacin did not increase protein loss through the intestinal mucosa, a process essentially related to changes of the microvascular endothelium..$^{1823}$ The intestinal permeability of hydrophilic macromolecules is limited by the integrity of the mucosal vasculature, the 'aqueous pores' of the luminal mem- 
brane of enterocytes, and the intercellular tight junctions. ${ }^{24}$ Our results show an increased epithelial permeability without apparent damage to the mucosal capillaries. There was probably not a change in enterocytes because there was no release of intracellular enzymes such as lactate dehydrogenase, and histological examination did not show enterocyte injury.

These results suggest that inhibition of endogenous prostaglandins was not the first stage of indomethacin induced permeability increase, as administration of exogenous synthetic analogues of prostaglandin $\mathrm{E}_{2}$ did not prevent the increased vascular to lumen ${ }^{51} \mathrm{Cr}$-EDTA transfer rate. Similar findings have been made in humans. ${ }^{25}$ The dose of dimethyl prostaglandin $\mathrm{E}_{2}$ given was selected from previous studies, ${ }^{21}{ }^{22}$ and should have been adequate to reverse indomethacin induced permeability changes, if these changes are a result of decreased prostaglandin synthesis. Furthermore, if cyclo-oxygenase inhibition was the main factor for the permeability increase, this effect would have been seen for much lower concentrations of indomethacin: in vitro, this drug inhibits cyclo-oxygenase at concentrations as low as $30 \mu \mathrm{M} .^{26}$

Thus, other mechanisms had to be found to explain the effects seen of high concentrations of indomethacin on small intestinal permeability. We showed that leukotrienes $\mathrm{B}_{4}$ and $\mathrm{D}_{4}$, as well as PAF, could increase vascular to lumen ${ }^{51} \mathrm{Cr}$ EDTA permeability. The mechanisms seemed to be different, however, from indomethacin induced changes, because of the dramatic vascular modifications, including major congestion of mucosal capillaries and increased vascular to lumen protein loss, seen with leukotrienes and PAF. It was noteworthy that leukotriene $D_{4}$ was more potent than leukotriene $B_{4}$, a finding consistent with the more specific action of leukotriene $\mathrm{D}_{4}$ on the tone and permeability of microvasculature. ${ }^{27}$ The effects of PAF, leukotriene $B_{4}$, and leukotriene $D_{4}$ on small intestinal permeability were specific for each molecule, as they could be prevented by the administration of their respective antagonists. These antagonists did not prevent, however, indomethacin induced permeability changes, suggesting that leukotrienes and PAF were not responsible for the early functional intestinal changes induced by the high doses of indomethacin used in this study.

Neutrophil accumulation in the intestinal mucosa has been recently shown to play an important part in the development of indomethacin induced intestinal ulcers. ${ }^{81028}$ This mechanism probably does not account for the present findings, because the suspension of washed erythrocytes used as perfusate contained less than 500 leucocytes $/ \mathrm{mm}^{3}$, and because no accumulation of polymorphonuclear cells was seen in the wall of intestinal loops at the end of perfusion experiments. We believe neutrophil accumulation to be only a part of the inflammatory response developed as a consequence of the initial indomethacin induced increased intestinal permeability.

From these data, inhibition of endogenous prostaglandins as well as enhanced production of leukotrienes and PAF probably do not explain the early permeability changes induced by indomethacin. Alternative mechanisms may be inferred from the ability of the molecule to act on other cellular enzymatic processes. ${ }^{29}$ Firstly, indomethacin, being a weak acid and a lipophilic molecule, can interfere directly with cell membranes to modify their functional properties. Secondly, indomethacin has recently been shown to change the cellular synthesis of adenosine triphosphate through the anaerobic glycolytic pathway ${ }^{30}$ : this also may increase the epithelial tight junction permeability, known to be energy dependent. ${ }^{31}{ }^{32}$ Thirdly, indomethacin can induce the release of oxygen derived free radicals $^{33}$ : these very unstable components may cause lipid peroxydation, producing functional changes of the intestinal barrier.

In conclusion, high concentrations of indomethacin can rapidly and selectively induce an increase of the small intestinal epithelial permeability, without any microscopical damage to enterocytes or mucosal vasculature. From our data, this effect does not seem to result from inhibition of endogenous prostaglandins synthesis alone, or from increased leukotriene and PAF production. Instead, indomethacin induced permeability changes may be a result of the synergistic action of the drug on several different metabolic processes. This would imply that any treatment strategy aimed at a single mechanism might fail to restore normal intestinal permeability.

F Mion was a recipient of a research grant from Smith Kline and Beecham Laboratories. The authors are grateful to F Berger, MD, for the realisation and analysis of histological slides. Part of this for the realisation and analysis of histological slides. Part of this work was presented in a poster session at the First United
European Gastroenterology Week, Athens, 25-30 September 1992.

1 Bjarnason I, Peters TJ. Intestinal permeability, non-steroidal anti-inflammatory drug enteropathy and inflammatory bowel disease: an overview. Gut (Festschrift) 1989; 30: 22-8.

2 Aabakken L. Review article: non-steroidal, anti-inflammatory drugs - the extending scope of gastrointestinal side effects. Aliment Pharmacol Ther 1992; 6: 143-62.

3 Fang WF, Broughton A, Jacobson ED. Indomethacininduced intestional inflammation. Dig Dis 1977; 22: 749-60.

4 Satoh H, Guth PH, Grossman MI. Role of food in gastrointestinal ulceration produced by indomethacin in the rat. Gastroenterology 1982; 83: 210-5.

5 Bjarnason I, Smethurst P, Clark P, Menzies I, Levi J, Peters TJ. Effect of prostaglandin on indomethacin-induced increased intestinal permeability in man. Scand $\mathcal{F}$ Gastroenterol 1989; 24 (suppl 164): 97-103.

6 Whittle BJR. Temporal relationship between cyclooxygenase inhibition, as measured by prostacyclin biosynthesis, and the gastrointestinal damage induced by indomethacin in the the gastrointestinal damage induced

7 Rainsford KD. Mechanisms of gastrointestinal toxicity of nonsteroidal anti-inflammatory drugs. Scand $\mathcal{F}$ Gastroenterol 1989; 25 (suppl 163): 9-16.

8 Miura S, Suematsu M, Tanaka S, Nagata H, Houzawa S, Suzuki M, et al. Microcirculatory disturbance in indomethacin-induced intestinal ulcer. Am F Physiol 1991; 261: G213-9.

9 Whittle BJR, Morishita T, Ohya Y, Leung FW, Guth PH. Microvascular actions of platelet-activating factor on rat G772-8.

10 Wallace JL, Keenan CM, Granger DN. Gastric ulceration induced by nonsteroidal anti-inflammatory drugs is a neutrophil-dependent process. Am F Physiol 1990; 259: neutrop

11 Wallace JL. Lipid mediators of inflammation in gastric ulcer. Am F Physiol 1990; 21: G1-11.

12 Karasawa A, Guo JP, Ma XL, Tsao PS, Lefer AM. Protective actions of a leukotriene $B_{4}$ antagonist in splanchnic ischemia and reperfusion in rats. Am $\mathcal{F}$ Physiol 1991; 261: G191-8.

13 Jones TR, Zamboni R, Belley M, Champion E, Charette $L$, Ford-Hutchinson AW, et al. Pharmacology of L-660,711 (MK-571): a novel potent and selective leukotriene $\mathrm{D}_{4}$ receptor antagonist. Can $\mathcal{F}$ Physiol Pharmacol 1989; 67 17-28.

14 Gillard J, Ford-Hutchinson AW, Chan C, Charleson S, Foster A, Fortin R, et al. L-663,536 (MK-886), a novel, orally Pharmacol 1989; 67: 456-64. 
15 Kubes P, Ibbotson G, Russell J, Wallace JL, Granger DN. Role of platelet-activating factor in ischemia/reperfusioninduced leukocyte adherence. Am $\mathcal{F}$ Physiol 1990; 259. G300-5

16 Cuber JC, Herrmann C, Kitabgi P, Bosshard A, Bernard C, De Nadai F, et al. Neuromedin-N is not released with neurtorensin from rat ileum. Endocrinology 1990; 126: 1584 92. 17 Beaven MA, Bayer BM. Factors influencing the uptake and Pharmacol 1980; 29: 2055-61.

18 Miller MJS, Zhang XJ, Gu X, Clark DA. Acute intestinal injury induced by acetic acid and casein: prevention by

19 Lowry OH, Rosebrough NJ, Farr AL, Randall RJ. Protein measurements with folin phenol reagent. $\mathcal{F}$ Biol Chem 1951; 193: 265-75.

20 Crissinger KD, Kvietys PR, Granger DN. Pathophysiology of gastrointestinal mucosal permeability. $\mathcal{F}$ Intern Med 1990; 228 (suppl 1): 145-54.

21 Yamada T, Specian RD, Granger DN, Gaginella TS, Grisham MB. Misoprostol attenuates acetic acid-induced increase in mucosal permeability and inflammation: role of blood flow. Am F Physiol 1991; 261: G332-9.

22 Krugliak P, Hollander D, Le K, Ma T, Dadufalza VD, Katz KD. Regulation of polyethylene glycol 400 intestina permeability by endogenous and exogenous prostanoids. permeability by endogenous and exogenous prostanoids. 1990; 31: 417-21.

23 Kubes $P$. Ischemia-r for nitric oxide. Am f Physiol 1993; 264: G143-9.
24 Anonymous. Intestinal permeability [Editorial]. Lancet 1985; i: 256-8.

25 Bjarnason I, Williams P, Smethurst P, Peters TJ, Levi AJ. Effects of non-steroidal anti-inflammatory drugs and prostaglandins on the permeability of the human small intestine. Gut 1986; 27: 1292-7.

26 Helleberg $\mathrm{L}$. Clinical pharmacokinetics of indomethacin Biochem Pharmacol 1982; 31: 3307-11.

27 Lehr HA, Guhlmann A, Nolte D, Keppler D, Messmer K. Leukotrienes as mediators in ischemia-reperfusion injury in a microcirculation model in the hamster. $\mathcal{F}$ Clin Invest 1991 ; 87: 2036-41.

28 Anthony A, Dhillon AP, Nygard G, Hudson M, Piasecki C, Strong $\mathrm{P}$, et al. Early histological features of small intestinal Strong $\mathrm{P}$, et al. Early histological features of small intestinal injury induced

29 Abramson SB, Weissmann G. The mechanisms of action of non-steroidal anti-inflammatory drugs. Arthritis Rheum 1989; 32: 1-9.

30 Hayllar J, Somasumdaram S, Sarathchandra P, Levi AJ Bjarnason I. Early cellular events in the pathogenesis of NSAID enteropathy in the rat. Gastroenterology 1991; 100 A216.

31 Duffey ME, Hainau B, Ho S, Bentzel CJ. Regulation of epithelial tight junction permeability by cyclic AMP. Nature 1981; 294: 451-3.

32 Gumbiner B. Structure, biochemistry, and assembly of epithelial tight junctions. Am $\mathcal{F}$ Physiol 1987; 253: C749-58.

33 Vaananen PM, Meddings JB, Wallace JL. Role of oxygenderived free radicals in indomethacin-induced gastric injury. Am F Physiol 1991; 261: G470-5. 